\title{
Kebijakan Pengadaan dan Customisasi CN-235 MPA (Maritime Patrol Aircraft) dalam Rangka Pengawasan Wilayah ZEE dan ALKI di Indonesia
}

\author{
Endro Tri Susdarwono ${ }^{a^{*}}$ \\ aniversitas Peradaban \\ a*Email: saniscara99midas@gmail.com
}

\begin{abstract}
ABSTRAK
Potensi sumber kekayaan alam maritim Indonesia merupakan salah satu target yang diinginkan oleh beberapa negara dari belahan dunia internasional untuk memperkuat perekonomian mereka. Di samping sumber kekayaan alam yang terkandung, Indonesia juga memiliki nilai strategis bagi perekonomian dunia. Potensi kekayaan alam maritim Indonesia, menuntut tersedianya keamanan maritim yang mumpuni yang dapat menjaga dari tindakan pelanggaran hukum, pencemaran lingkungan, eksploitasi sumber daya alam, bahaya navigasi, dan pelanggaran wilayah. Maritime Patrol Aircraft (MPA) merupakan alat yang dianggap tepat untuk menjaga keamanan di lingkungan maritim. Tujuan penelitian ini adalah untuk menggambarkan pengadaan dan customisasi N-235 MPA dalam rangka pengawasan dan pengamanan wilayah ZEE dan ALKI di Indonesia. Penelitian ini menggunakan pendekatan deskriptif. Jenis penelitian ini adalah deskriptif kualitatif. Hasil dari penelitian menunjukkan bahwa Maritime Patrol Aircraft dengan spesifikasi berupa pesawat kecil (medium range aircraft) yang irit bahan bakar dan tidak membutuhkan landasan pacu yang panjang, untuk mendarat sehingga mampu mendarat di landasan darurat (airship) sekalipun. Pesawat ini sesuai untuk menjangkau seluruh wilayah perbatasan laut yang sulit diakses dalam mendeteksi adanya aktivitas yang mencurigakan, khususnya di wilayah ZEE dan ALKI. Pesawat ini memiliki radar dengan cakupan monitor yang luas, kamera pengintai, dan sistem persenjataan yang canggih.
\end{abstract}

Kata Kunci: ALKI, CN-235 MPA. ZEE

\section{ABSTRACT}

The potential of Indonesia's maritime natural resources is one of the targets desired by several countries from the international world to strengthen their economy. In addition to the natural resources it contains, Indonesia also has a strategic value for the world economy. The potential of Indonesia's maritime natural wealth demands the availability of qualified maritime security that can guard against acts of lawlessness, environmental pollution, exploitation of natural resources, navigational hazards, and territorial violations. Maritime Patrol Aircraft (MPA) is a tool that is considered appropriate to maintain security in the maritime environment. The purpose of this study is to describe the procurement and customization of N-235 MPA in the context of monitoring and securing the EEZ and ALKI areas in Indonesia. This study uses a descriptive approach. This type of research is descriptive qualitative. The result of the research is that the Maritime Patrol Aircraft with specifications in the form of a small aircraft (medium range aircraft) that is fuel efficient and does not require a long runway, to land so that it can land on an emergency runway (airship). This aircraft is suitable for reaching all sea border areas that are difficult to access in detecting suspicious activity, especially in the EEZ and ALKI areas. This aircraft has a radar with a wide range of monitors, surveillance cameras, and sophisticated weapons systems.

Keywords: ALKI, CN-235 MPA. EEZ 


\section{PENDAHULUAN}

Indonesia sering dilekatkan dengan julukan negara kepulauan (archipelago state), hal ini dikarenakan secara geografis, Indonesia merupakan negara dengan wilayah laut terbesar di dunia. Dengan luas wilayah laut 3,1 juta $\mathrm{km}^{2}$ dan panjang garis pantai $81.000 \mathrm{~km}$, tersebar 17.508 pulau besar dan kecil sehingga kita mengenal juga istilah "Tanah Air" yang merupakan pemaduan dua kata (air dan tanah) (Hamid, 2013).

Pada tanggal 13 Desember 1957, telah diputuskan archipelagic states dalam Deklarasi Djoeanda yang menyatakan bahwa Indonesia berdaulat penuh di perairan antar pulau. Hasil dari Deklarasi Djoeanda diakui oleh PBB sejak 1982 melalui UNCLOS dengan pengakuan terhadap bentuk negara kepulauan (Anshoriy dan Arbaningsih, 2008). Di wilayah Asia Tenggara, selain animo kerjasama yang makin erat, terdapat pula potensi ancaman-ancaman perselisihan mengenai perbatasan, penangkapan ikan secara ilegal, masalah Choke Points (Sea Lines of Communication/SLOC), masalah bahan strategis, maupun masalah minyak lepas pantai (Bagyo, 1996).

Luasnya wilayah Zona Ekonomi Eksklusif (ZEE) di Indonesia, menuntut adanya pembangunan Maritime Domain Awaraness (MDA). UNCLOS 1982 mengharuskan Indonesia menentukan sebagian wilayah perairannya menjadi jalur lalu lintas laut yang saat ini disebut sebagai Alur Laut Kepulauan Indonesia (ALKI) utara-selatan. Desakan muncul dari berbagai negara di Asia Pasifik agar Indonesia segera menetapkan ALKI timur-barat. Di sisi lain Indonesia beranggapan bahwa ALKI yang telah ada, dilengkapi dengan hak lintas damai sebagaimana diatur dalam UNCLOS 1982, telah memenuhi kepentingan pelayaran internasional (Marsetio, 2014).

Masing-masing ALKI memiliki potensi ancaman yang dinilai relevan dan membutuhkan koordinasi yang lebih serius. Penelitian Marbun (2016) tentang hak dan kewajiban kapal dan pesawat udara asing melakukan lintas di alur laut kepulauan Indonesia menyatakan bahwa selain memiliki letak yang strategis sebagai penghubung Samudera Hindia dan Samudera Pasifik, kawasan di sekitar alur laut kepulauan II menyimpan potensi sumber daya alam yang melimpah sehinggga wilayah tersebut rawan terhadap terjadinya berbagai tindak pelanggaran hukum maupun pelanggaran wilayah kedaulatan yang dapat mengancam integritas nusantara, sedangkan Yustitianingtyas (2015) dalam penelitian tentang pengamanan dan penegakan hukum di perairan Indonesia sebagai konsekuensi penetapan Alur Laut Kepulauan Indonesia (ALKI) menyatakan bahwa meskipun telah dilaksanakan kerjasama antara angkatan laut Indonesia dengan angkatan laut negara lain, akan tetapi kasus perompakan masih sering terjadi, hal ini dikarenakan luasnya serta minimnya kapal patroli untuk menegakkan keamanan di lautan.

Sementara penelitian Harris et al (2019) menyimpulkan bahwa beberapa tipe ancaman keamanan terkini yang cukup kompleks yang dihadapi Indonesia sebagai sebuah negara kepulauan dan juga maritim yang datang dari meningkatnya ketegangan dan eskalasi konflik di Laut China Selatan, serta dari terorisme global, intervensi asing, dan beragam kejahatan lainnya. Hal ini sejalan dengan penelitian Rustam (2021) yang menyimpulkan bahwa ancaman keamanan pada tiga jalur ALKI menjadi tantangan bagi pemerintah Indonesia dalam menuju cita-cita poros maritim.

Pengadaan alat utama sistem senjata (alutsista) adalah kegiatan untuk memperoleh barang/alutsista TNI yang prosesnya dimulai dengan perencanaan kebutuhan sampai diterimanya alutsista TNI yang berfungsi sesuai dengan 
peruntukannya. Pengembangan kekuatan alutsista TNI adalah kegiatan pengadaan alutsista TNI yang menghasilkan penambahan jumlah dan/ atau jenis alutsista TNI (Peraturan Menteri Pertahanan Republik Indonesia Nomor 34 Tahun 2011).

Pengadaan alutsista TNI dilakukan melalui pemilihan penyedia alutsista TNI berdasarkan Peraturan Menteri meliputi alutsista Luar Negeri dan alutsista Dalam Negeri, dengan ketentuan: (1) Pengadaan alutsista TNI wajib menggunakan produksi dalam negeri. (2) Dalam hal alutsista TNI sebagaimana dimaksud pada ayat (1) belum dapat dipenuhi oleh Industri Pertahanan Dalam Negeri, pengadaan produk luar negeri dapat dilaksanakan melalui proses langsung antar pemerintah atau kepada pabrikan (Peraturan Menteri Pertahanan Republik Indonesia Nomor 17 Tahun 2014).

Tujuan dari pengadaan alutsista terkait keamanan maritim adalah untuk melindungi wilayah ZEE dan ALKI dengan melakukan kegiatan pengawasan dan pengamanan di wilayah ZEE dan ALKI. Dengan demikian, untuk mendukung tugas dan fungsi maka, dibutuhkan C4ISR capabilities system, BVR (Beyond Visual Range), Radar, Medium Range Missile, UAV/UCAV, Maritime Patrol Surveillance Aircraft, Heli Ship/ Airstrips, Interceptor Planes. Namun, dengan pertimbangan keterbatasan anggaran, tingkat ancaman dan kesiapan sumber daya, alutsista yang memungkinkan untuk dibeli adalah MPS Aircraft.

Sebagai jenis pesawat intai, $\mathrm{CN}$ 235 MPA diharapkan mampu memberikan informasi yang mutakhir melalui radar dengan kualitas canggih yaitu Elletronica ALR 733 Radar Warning Receiver, radar Ocean Master 100 buatan Thales (pilihan lain radar Seaspray 4000 dari BAe System), dan perangkat lihat malam (FLIR-Forward Looking Infrared). Dengan FLIR ini,
CN235 MPA memiliki penglihatan ekstra sehingga mampu beroperasi pada malam hari. Tak hanya itu, pesawat ini juga membawa Magnetic Anomaly Detector (MPA) yang berfungsi untuk mengetahui lokasi kapal selam.

Penelitian ini mendeskripsikan pengadaan dan customisasi N-235 MPA (Maritime Patrol Aircraft) dalam rangka pengawasan dan pengamanan wilayah ZEE (Zona Ekonomi Eksklusif) dan ALKI (Alur Laut Kepulauan Indonesia) di Indonesia.

\section{METODE}

Pendekatan dalam penelitian ini menggunakan metode pendekatan deskriptif untuk memaparkan atau menggambarkan pengadaan dan customisasi N-235 MPA (Maritime Patrol Aircraft) dalam rangka pengawasan dan pengamanan wilayah ZEE (Zona Ekonomi Eksklusif) dan ALKI (Alur Laut Kepulauan Indonesia) di Indonesia.

Jenis penelitian yang digunakan adalah penelitian deskriptif kualitatif, yaitu mendeskripsikan dan menginterpretasikan mengenai kondisi/ hubungan yang ada, proses yang sedang berlangsung pendapat yang sedang tumbuh, kecenderungan yang tengah berkembang atau akibat/efek yang terjadi. Teknik pengumpulan data meliputi Forum Group Discussion, dokumen, sedangkan analis data meliputi: reduksi, penyajian data, dan verifikasi data.

\section{HASIL DAN PEMBAHASAN}

Fokus perhatian global terhadap keamanan maritim Kawasan ASEAN, termasuk Asia Timur, dan Pasifik menjadi perhatian utama. Berbagai kalangan fokus pada permasalahan bidang kemaritiman. Kondisi demikian menjadi menarik untuk dibahas serta dianalisis, karena perairan yurisdiksi nasional sebagai urat nadi atau jalur Sea Lane of Trade (SLOT) dan Sea Lane of 
Communication (SLOC) sangat padat, satu sisi mengandung nilai ekonomi dan sisi lain mengandung kerawanankerawanan yang harus diantisipasi serta ditindaklanjuti secara cerdas oleh seluruh pemangku kepentingan (Susanto dan Munaf, 2015).

Luas terumbu karang yang terdapat di perairan Indonesia diperkirakan lebih dari $60.000 \mathrm{~km}^{2}$, yang tersebar luas dari perairan kawasan barat Indonesia sampai kawasan timur Indonesia.

Keempat, potensi Alur Laut Kepulauan Indonesia (ALKI). Tanpa di sadari, sudah lima puluh tahun lebih, sejak Deklarasi Juanda 1957, bangsa ini seakan membiarkan potensi tiga ALKI yang dimiliki untuk dilalui begitu saja oleh kapal-kapal asing yang lalu lalang. Padahal, melalui tiga ALKI yang masing-masing ALKI I melintasi Laut Cina Selatan-Selat Karimata-Laut Jakarta-Selat Sunda, ALKI II melintasi Laut Sulawesi-Selat Makassar-Laut Flores-Selat Lombok, dan ALKI III melintasi Samudera Pasifik-Selat Maluku, Laut Seram-Laut Banda, Indonesia bisa meraup devisa miliaran rupiah setiap tahunnya. Bandingkan dengan Singapura yang hanya senggolan jalur perdagangan dunia mampu memanfaatkan kondisinya dengan meraup devisa yang besar buat negaranya. (Salim, 2014).

Potensi sumber kekayaan alam maritim Indonesia merupakan salah satu target yang dilirik dan diinginkan oleh beberapa negara dari belahan dunia internasional untuk memperkuat perekonomian mereka. Kecenderungan ini semakin eskalatif karena di samping sumber kekayaan alam yang terkandung, Indonesia juga memiliki nilai yang sangat strategis bagi perekonomian dunia. Hal ini mengingat jalur transportasi laut Sea Lane of Communication (SLOC) maupun Sea Lane of Trade (SLOT) bagi kapal-kapal super besar VLCC, ULCC yang berukuran di atas 300.000 dwt melalui Selat Malaka maupun Alur Laut Kepulauan Indonesia (ALKI) dimanfaatkan oleh pihak-pihak negara asing sebagai jalur perdagangan dunia (Susanto dan Munaf, 2015).

Karena itu, Indonesia mempunyai kepentingan yang sangat besar dalam keamanan maritim, yaitu tujuannya wajib diarahkan untuk mencapai dan membentuk kondisi yang kondusif menurut ancaman pelanggaran area dari pihak luar; aman bahaya navigasi pelayaran, eksploitasi ilegal sumber daya alam dan pencemaran lingkungan; dan aman dari tindakan pelanggaran hukum.

\section{Dasar Pertimbangan Pengadaan N-235 MPA}

Undang-Undang No. 3 Tahun 2001 tentang Pertahanan Negara, Pasal 4 tujuan utama pertahanan negara adalah untuk menjaga dan melindungi kedaulatan negara, keutuhan wilayah Negara Kesatuan Republik Indonesia, dan keselamatan segenap bangsa dari segala bentuk ancaman.

Buku Strategi dan Postur Pertahanan Keamanan Negara Dalam Jangka Panjang Kedua Tahun 19942018 (Revisi TA 1997-1998) yang diterbitkan Departemen Pertahanan, postur pertahanan (defence posture) merupakan "wujud kemampuan dan kekuatan serta gelar Hankamneg (pertahanan keamanan negara) yang diharapkan dapat mendukung pelaksanaan strategi dalam mencapai sasaran dan tujuan Hankamneg." Postur pertahanan memiliki tiga aspek utama, yakni kemampuan (capability), kekuatan (force)-elemen-elemen tempur dan gelar (deployment) - tata sebar kekuatan.

UU Nomor 34 Tahun 2004 tentang TNI, Pasal 6 : Fungsi TNI sebagai penangkal terhadap setiap bentuk ancaman militer dan ancaman bersenjata dari luar dan dalam negeri terhadap kedaulatan, keutuhan wilayah, 
dan keselamatan bangsa. Sesuai dengan UU tersebut, tugas-tugas TNI AU untuk melaksanakan operasi udara dalam rangka penegakan kedaulatan di udara, darat dan laut harus memiliki kekuatan pemukul udara, kekuatan intai udara, dan kekuatan lintas udara. Alutsista yang diharapkan untuk mendukung kekuatan intai udara:

1. Pesawat intai udara strategis, untuk pengintaian sampai di luar batas ZEE.

2. Pesawat intai udara taktis, untuk pengintaian secara detail daerah pertempuran baik pesawat berawak maupun tak berawak.

Doktrin Swa Bhuwana Paksa, dijelaskan tugas TNI AU dalam kegiatan operasi militer untuk perang (OMP) dan operasi militer selain perang (OMSP). Dalam OMP, salah satu tugas TNI AU adalah Operasi Serangan Udara Strategis, meliputi kegiatan Operasi Pengamatan dan Pengintaian Udara Strategis, Operasi Penyerangan Udara dan Operasi Perlindungan Udara. Sementara, dalam OMSP, salah satu tugas TNI AU adalah mengamankan wilayah perbatasan, membantu pemerintah untuk pengamanan pelayaran dan penerbangan terhadap pembajakan, perompakan dan penyelundupan.

Sesuai dengan UU Nomor 3 Tahun 2001, Buku Strategi dan Postur Pertahanan Keamanan Negara, UU Nomor 34 Tahun 2004, Doktrin Swa Bhuwana Paksa TNI AU tentang fungsi dan tugas TNI AU dalam pengamanan wilayah kedaulatan NKRI, maka alutsista yang dibutuhkan matra udara adalah Maritime Patrol Aircraft dengan spesifikasi berupa pesawat kecil (medium range aircraft) yang irit bahan bakar dan tidak membutuhkan landasan pacu yang panjang, untuk mendarat sehingga mampu mendarat di landasan darurat (airship) sekalipun. Pesawat ini diharapkan mampu menjangkau seluruh wilayah perbatasan laut yang sulit diakses untuk mendeteksi adanya aktivitas yang mencurigakan, khususnya di wilayah ZEE. Pesawat ini diharapkan memiliki radar dengan cakupan monitor yang luas, kamera pengintai, dan sistem persenjataan yang canggih.

Produk CN-235 MPA merupakan pesawat yang tepat dalam pengawasan maritim, terlebih Indonesia yang merupakan negara maritim. Namun, pembelian pesawat ini sangat minim, bahkan KEMHAN dan TNI membeli pesawat sejenis dari negara lain. Hal ini terlihat adanya suatu hubungan yang kompleks antara PT DI dengan KEMHAN TNI dan Parlemen.

\section{Spesifikasi N-235 MPA}

Produk ini digunakan sebagai regional airliner dan military transport. Fungsi CN-235 MPA sebagai maritime patrol, surveillance, dan air transport, search and rescue (SAR), pengawasan Zona Eksklusif Ekonomi, marine pollution prevention and control, antisubmarine dan anti-surface warfare.

$\mathrm{CN}-235$ MPA merupakan medium class aircraft, didukung peralatan dengan fasilitas patroli dan kemampuan pengawasan (control) territorial laut lepas. Berbeda dengan $\mathrm{CN}-235$, pesawat patroli pesanan TNI$\mathrm{AL}$ ini menggunakan desain winglet pada ujung sayap. Winglet dipercaya mampu mengefisienkan gaya hambat, yang juga penghematan bahan bakar. Dengan penghematan bahan bakar ini, CN 235 MPA bisa lebih lama di udara yaitu memiiki daya tahan 11 jam dan waktu di stasiun pada jarak 200nm memiliki ketahanan 9 jam, sehingga cocok untuk operasi maritim.

CN-235 MPA memiliki spesifikasi sebagai berikut.

Jumlah awak: dua pilot dan co-pilot.

Kapasitas: 44 penumpang.

Pembangkit listrik: $2 \times$ General Electric CT7-9C3 turboprops, $1,305 \mathrm{~kW}(1,750$ hp) (take-off); $1.750 \mathrm{shp;} \mathrm{S.L;} \mathrm{Static}$ Take-off dengan APR. 


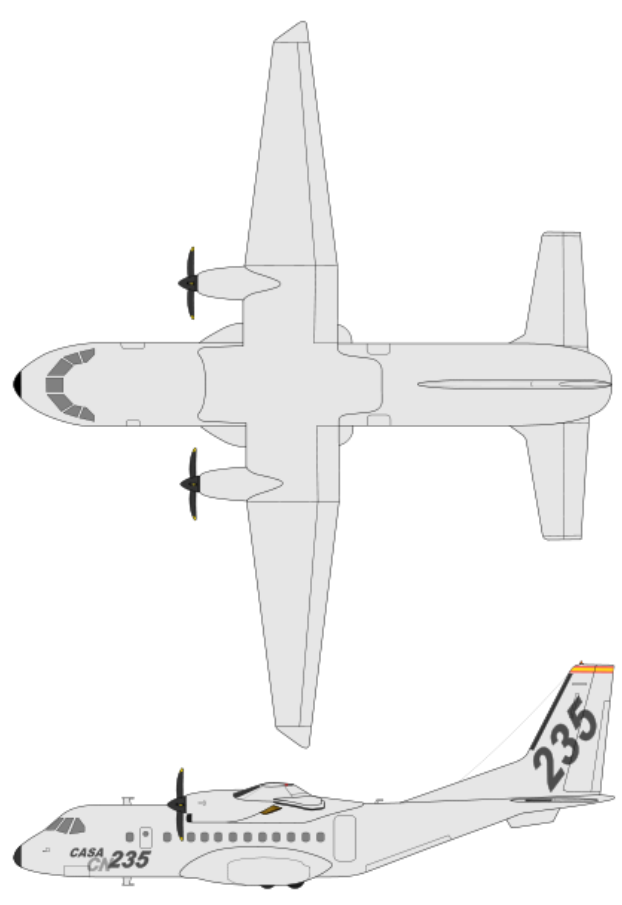

Gambar 1. CN-235 MPA

Beban maksimal:

1. Max Taxi Weight $16.100 \mathrm{~kg}$;

2. Max Take-off Weight $16.000 \mathrm{~kg}$;

3. Max Landing Weight 15.800kg;

4. Max Zero Fuel Weight 14.900kg;

5. Max Usable Fuel Capacity 4.000kg.

Dimensi:

1. Overall Span $25,81 \mathrm{~m}$;

2. Overall Length $22,89 \mathrm{~m}$;

3. Overall Height 8,12m;

4. Gross Wing Area $61,00 \mathrm{~m}$;

5. Wheel Track 3,90 $\mathrm{m}^{2}$;

6. Wheel Base 6,92m.

Kemampuan:

1. Condition :MTOW, ISA, 10.000ft;

2. Maximum Speed 225 ktas;

3. Long Range Speed 186 ktas;

4. Max Endurance Speed 147 ktas;

5. Max Range $1.665 \mathrm{~nm}$;

6. Max Endurance 8.55 hrs.

Pesawat ini digunakan untuk melakukan sejumlah tugas tertentu yang akan meningkatkan program keamanan, meliputi:

1. Melakukan pengawasan pada siang dan malam hari secara efektif untuk mendeteksi aktivitas penyusupan dan mengkoordinasikan upaya penangkapan.
2. Menjangkau wilayah perbatasan darat yang sulit diakses untuk mendeteksi adanya aktivitas yang mencurigakan.

3. Meninjau aktivitas perikanan, anti penyelundupan, anti narkoba, dan kontrol imigrasi.

4. Kemampuan menyerang pada target permukaan (dari kapal patroli kecil dan cepat untuk kapal bersenjata besar) bertindak mandiri atau kerjasama.

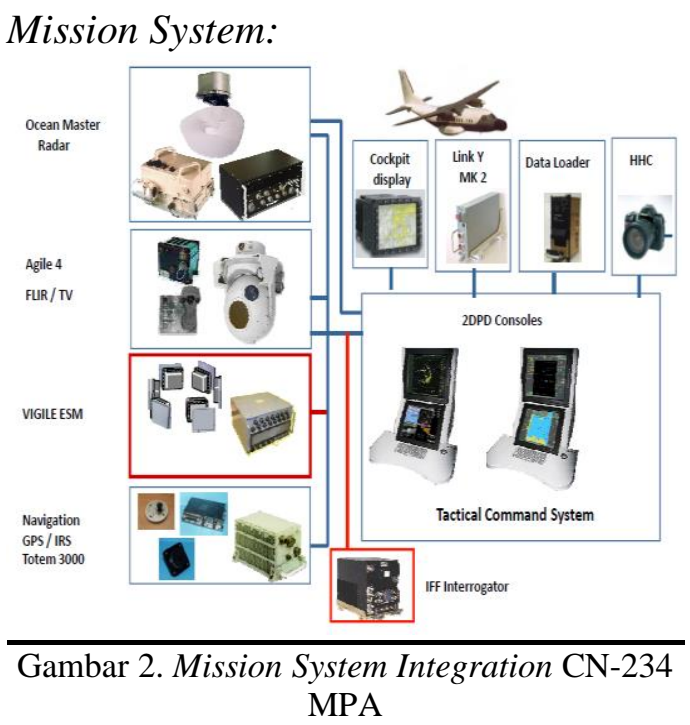

CN-235 MPA dibuat dengan menggunakan Amascos 200 mission sistem, yaitu:

1. Search radar (Seaspray 4000 radar dibuat oleh BAE System dan Radar AN/APS-134 dari Raytheon or the Ocean Master 100 from Litton, Texas Instruments, Thales, ELTA).

Ocean Master 400 terdiri dari 3 komponen, yaitu antena, transmitter, dan unit prosesor. Dalam operasionalnya, perangkat ini dimonitor oleh seorang awak. Antena punya dimensi 955 x $350 \mathrm{~mm}$ dengan bobot $16 \mathrm{~kg}$. Kecepatan rotasi antena radar yaitu 6 hingga 30 rpm, sementara untuk jangkauan bisa mencakup 360 derajat, atau bila secara sektoral $60-120$ derajat. Bobot 3 komponen secara keseluruhan hanya sekitar $80 \mathrm{~kg}$. 


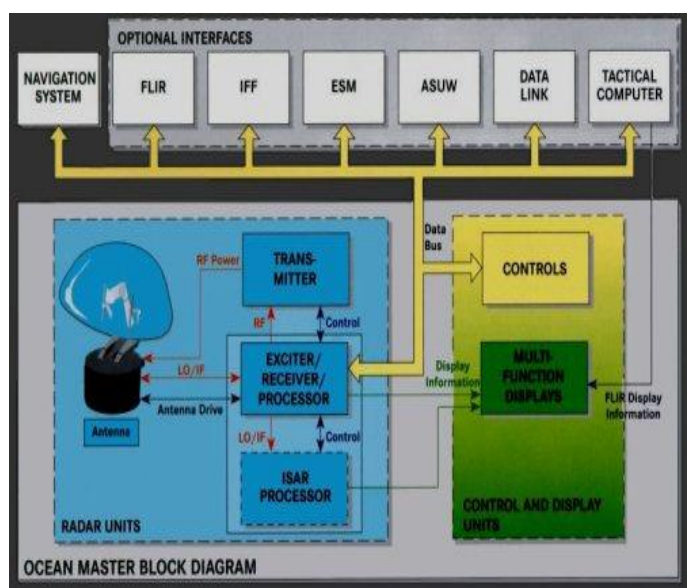

Gambar 3. Sistem Integrasi Radar Ocean Master dengan AMASCOS

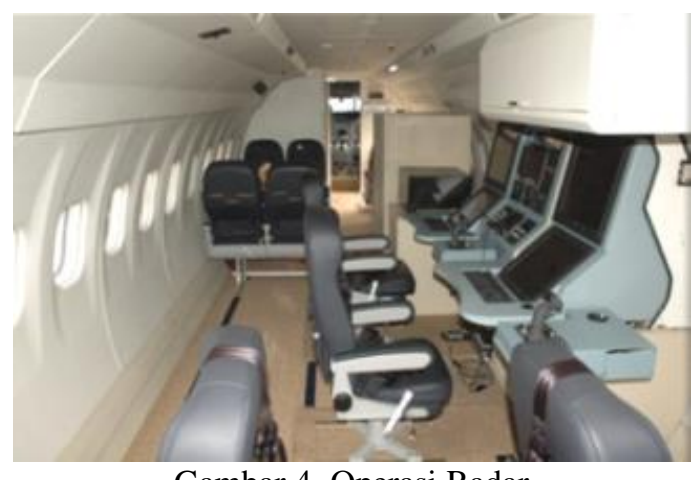

Gambar 4. Operasi Radar

Ocean Master mampu melakukan scanning mencapai dua ratus sasaran sekaligus sehingga dapat difungsikan sebagai pengintai kapal permukaan, ASW (anti submarine warfare), pengintaian ZEE (zona ekonomi eksklusif), misi SAR (search and rescue), anti penyelundupan, hingga dapat memindai jejak tumpahan minyak di lautan lepas. Dalam melakukan deteksi jarak jauh, secara teoritis dapat menjangkau hingga dua ratus nautical mile $(370,4 \mathrm{~km})$. $\mathrm{CN}$ 235 yang dimiliki TNI AL memiliki kelebihan di sisi radar bawah perut pesawat (belly dome radar). Model seperti ini berkemampuan untuk memonitor target di belakang pesawat.

2. FLIR Safire III (Forward Looking Infra Red), buatan GEC Marconi, WesCam, Thales, FSI.

FLIR SAFIRE III di CN-235 MPA TNI AL sudah dapat mengidentifikasi kapal-kapal nelayan pada ketinggian
13.000 kaki (setara $4 \mathrm{~km}$ ). Dalam modul FLIR SAFIRE III atau disebut sebagai gyro-stabilized EO (electro optical)/IR (infra red) systems, dapat membawa hingga 7 perangkat sensor yang terdiri dari low light camera, laser rangefinder, thermal imager dengan $71 \mathrm{x}$ zoom, spotter scope, color zoom camera dan digital IMU/GPS. Selain dapat berputar 360 derajat, modul FLIR dapat memainkan sudut elevasi mulai dari $+30^{0}$ hingga $-120^{\circ}$. Modul bekerja dalam 5 axis stabilization. FLIR SAFIRE III memiliki bobot $44 \mathrm{~kg}$ dengan dimensi 380 x $450 \mathrm{~mm}$. FLIR SAFIRE III hanya dapat dioperasikan dalam kondisi ideal, yaitu $-40^{\circ} \mathrm{C}$ sampai $55^{\circ} \mathrm{C}$ karena merupakan perangkat dengan paduan sensor sensitif.

Meski dikenal dalam istilah militer, FLIR juga memiliki andil besar dalam kegiatan sipil. Sebut saja dalam pencarian titik panas (hotspot) saat kebakaran hutan dan mencari orang yang hilang di hutan. Dalam misi militer, FLIR kerap digunakan untuk proteksi pada VIP, menetralisir posisi sniper, pengintaian di padang pasir, intai di lautan saat gelombang tinggi, dan masih banyak lainnya. Kabarnya, lebih dari 500 FLIR SAFIRE III kini telah terpasang diberagam wahana.

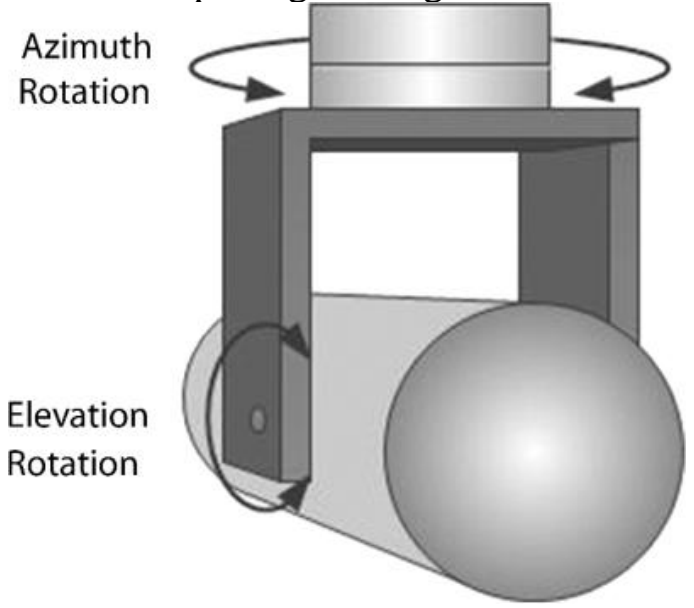

Gambar 5. FLIR

3. IFF Interrogator

$\begin{array}{lll}\text { 4. Tactical } & \text { Navigation/ } & \text { FMS } \\ \text { (Northrop } & \text { Grumman-built } & \text { LN92 }\end{array}$ 
ring laser gyroscope inertial navigation system)

5. Tactical Computer System

6. Day Light TV/Camera

7. Bubble Window

8. Anti Jamming VHF/UHF

9. Independent Inertial System

10. Video and Data Link

11. Data Handling/ Recording

12. Digital Communication System

13. Operator is flexible to select the mission system

14. Electronic warfare (ESM / ECM and ELINT / COMINT) dibuat oleh Boeing ARGO System, GEC Marconi, Thales

$\mathrm{CN}-235$ MPA didukung oleh dua General Electric CT\&-9C3 turboprop engines dan propellers dimana glass fibre construction menggunakan metal spar dan urethane foam core, desain fitur pesawat konvensional semi-monocoque dan terutama dari aluminium konstruksi alloy. Fitur tambahan pesawat termasuk Trimble TNL7900 Omega global positioning system. Aircraft Technology (AirTech), merupakan joint venture antara EADS CASA dan PT DI. Perusahaan elektronik pesawat dan defence system Thales, telah menandatangani MoU dengan PT DI pada Mei 2000 untuk menyuplai piranti AMASCOS yakni, Airborne Maritime Situation Control System, termasuk juga Ocean Master search radar produksi Thales dan EADS. MoU itu juga meliputi pengadaan piranti: Eletronica ALR 733 radar warning receiver, The Chlio thermal imager buatan Thales Optronique, Gemini navigation computer dari Thales Avionics serta AN/ASQ-508 magnetic anomaly detection (MAD) system dari CAE.

CN 235 MPA ini dilengkapi tiga hardpoints di bawah masing-masing sayapnya yang mampu membawa rudal anti kapal Harpoon. CN 235 MPA Indonesia mampu membawa dua torpedo mk46 atau exocet M-39 airlaunch anti-ship missiles. Hardpoint sisanya kemungkinan ditujukan untuk mengangkut rudal anti pesawat, sebagai pertahanan diri.

CN-235 merupakan hasil kerja sama fifty-fifty antara CASA Spanyol (sekarang Airbus Military) dengan PT DI. Kedua produsen pesawat terbang ini lalu memilih mengembangkan sendiri $\mathrm{CN}-235$ versi patroli maritimnya sehingga pesawat maritim yang dihasilkan juga berbeda-beda.

\section{Proses Pengadaan CN-235 MPA}

Produk ini merupakan co-production antara Construcciones Aeronauticas SA (CASA) dan Indonesian Aerospace (PT. Dirgantara Indonesia). EADS CASA membuat kerangka depan dan sayap tengah, sedangkan IPTN membuat kerangka belakang, panil sayap luar, dan permukaan ekor.

PTDI mengembangkan MPS aircraft jenis CN 235 MPA bekerjasama dengan CASA Spanyol (airbus military) secara fifty-fifty. Engine masih diproduksi oleh CASA, sementara hard material diproduksi oleh PTDI dan industri lokal pendukungnya. Untuk menambah pesawat CN 235 MPA, TNI AU akan membeli kembali produk ini beberapa skuadron untuk ditempatkan di lanud titik strategis pengamanan wilayah ZEE dengan menambahkan spec-spec seperti upgrade radar, image sensing dan SMR.

Untuk pengadaan MPS menggunakan Proffered supplier yaitu PTDI untuk CN 235 MPA, PT. Dahana untuk teknologi persenjataannya (rudal dan SMR), PT LEN untuk radar, dan PT Inti untuk image sensing. Project type dalam pengadaan MPS berupa Close, yaitu tujuan dari pengadaan MPS ini jelas untuk pengawasan dan pengamanan wilayah ZEE, metode yang dilakukan adalah custom (penambahan spec atau upgrade beberapa spec oleh inhan-PTDI). Kemhan/TNI AU memberikan kapabilitas yang 


\section{CUSTOMER POINT OF VIEW MATRIX}
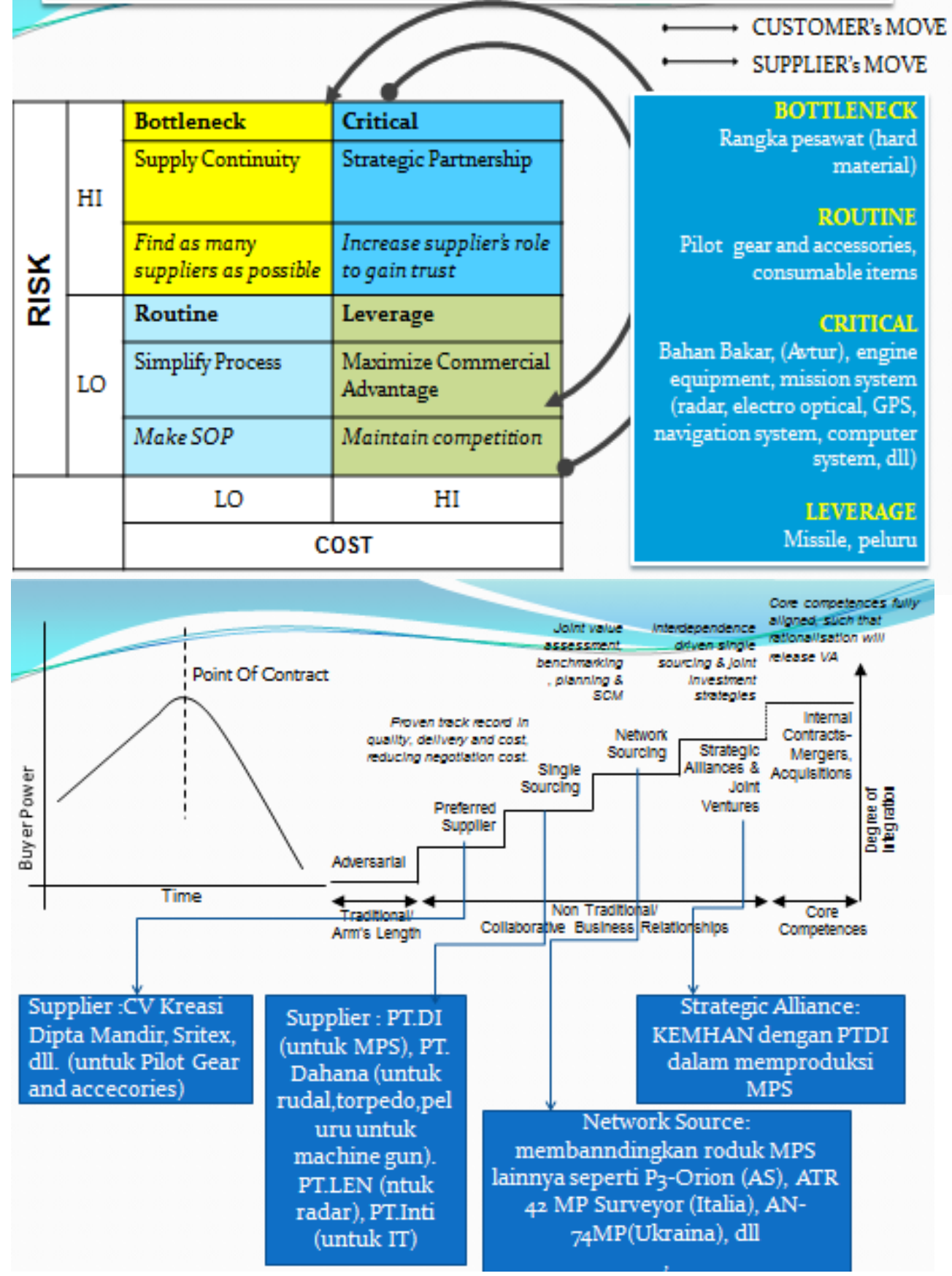

Gambar 6. Customer Point of View Matrix

diinginkan, PTDI yang akan memenuhi keinginan KEMHAN/TNI AU sebagai user.

Jenis required capability enduring adalah long term acquisition, dengan memperhatikan CADMID (concept, assessment, demonstration, manufacturing, in-service, dan disposal). Solusi cost-effective adalah TCPR thrue life across DLODs. Sementara manage its delivery berupa penambahan unit untuk melengkapi kelengkapan unit yang ada, penempatan unit yang sudah ada pada titik rawan perbatasan laut antar negara, up grade dengan dilengkapi persenjataan SMR (senapan mesin ringan).

\section{SIMPULAN}

Berdasarkan pertimbangan tujuan dari pengadaan alutsista terkait keamanan maritim untuk melindungi wilayah ZEE dan ALKI dengan 
melakukan kegiatan pengawasan dan pengamanan di wilayah ZEE dan ALKI serta spesifikasi yang dimiliki N-235 MPA, maka pengadaan N-235 MPA merupakan suatu keharusan dan konsekuensi yang logis bagi Indonesia. Namun demikian pengadaan N-235 MPA juga harus disertai dengan customisasi yang sesuai dengan kondisi dan kebutuhan. Maritime Patrol Aircraft dengan spesifikasi berupa pesawat kecil (medium range aircraft) yang irit bahan bakar dan tidak membutuhkan landasan pacu yang panjang, untuk mendarat sehingga mampu mendarat di landasan darurat (airship) sekalipun. Pesawat ini diharapkan mampu menjangkau seluruh wilayah perbatasan laut yang sulit diakses untuk mendeteksi adanya aktifitas yang mencurigakan, khususnya di wilayah ZEE dan ALKI. Pesawat ini diharapkan memiliki radar dengan cakupan monitor yang luas, kamera pengintai, dan sistem persenjataan yang canggih.

\section{DAFTAR PUSTAKA}

Anshoriy, C, Nasurddin, \& Arbaningsih, D. (2009). Negara Maritim Nusantara: Jejak Sejarah yang Terhapus. Tiara Wacana.

Bagyo, H. (1996). Perang Abad 21 dan Sishankamrata. Gramedia Pustaka Utama.

Hamid, A.R. (2013). Sejarah Maritim Indonesia. Penerbit Ombak.

Harris, A., Prakoso, L.Y., \& Sianturi, D. (2019). Strategi Pertahanan Laut dalam Rangka Ancaman Keamanan Di Alur Laut Kepulauan Indonesia II. Jurnal Strategi Pertahanan Laut, 5(1), 15-30.

Marbun, V. (2016). Hak dan Kewajiban Kapal dan Pesawat Udara Asing Melakukan Lintas di Alur Laut Kepulauan Indonesia. Sumatra Journal of Intenational Law, 2(1), 12-23.

Marsetio. (2014). Sea Power Indonesia. Universitas Pertahanan.
Republik Indonesia. 2011. Peraturan Menteri Pertahanan Republik Indonesia Nomor 34 Tahun 2011 tentang Pelaksanaan Pengadaan Alat Utama Sistem Senjata di di Lingkungan Kementerian Pertahanan dan Tentara Nasional Indonesia. Jakarta: Kementerian Pertahanan.

Republik Indonesia. 2004. Undangundang Republik Indonesia Nomor 34 Tahun 2004 tentang TNI. Jakarta: Presiden Republik Indonesia.

Republik Indonesia. 2014. Peraturan Menteri Pertahanan Republik Indonesia Nomor 17 Tahun 2014 tentang Pedoman Pelaksanaan Pengadaan Alat Utama Sistem Persenjataan Tentara Nasional Indonesia di Lingkungan Kementerian Pertahanan dan Tentara Nasional Indonesia. Jakarta: Kementerian Pertahanan.

Rustam, I. (2021). Tantangan ALKI dalam Mewujudkan Cita-Cita Indonesia Sebagai Poros Maritim Dunia. Indonesian Perspective, 1(1), 1-21.

Salim. (2014). Kodrat Maritim Nusantara: Catatan Strategis Kemaritiman. LeutikaPrio.

Susanto \& Dicky R.M. (2015). Komando dan Pengendalian Keamanan dan Keselamatan Laut: Berbasis Sistem Peringatan Dini. PT Gramedia Pustaka Utama.

Yustitianingtyas, L. (2015). Pengamanan dan Penegakan Hukum di Perairan Indonesia sebagai Konsekuensi Penetapan Alur Laut Kepulauan Indonesia (ALKI). Pandecta, 10(2), 144-152. 